\title{
Pharmacokinetics and Pharmacogenomics of Bupropion in Three Different Formulations with Different Release Kinetics in Healthy Human Volunteers
}

\author{
Jamie N. Connarn, ${ }^{1}$ Stephanie Flowers, ${ }^{2}$ Marisa Kelly, ${ }^{3}$ Ruijuan Luo, ${ }^{1}$ Kristen M. Ward, ${ }^{2}$ Gloria Harrington, ${ }^{3}$ \\ Ila Moncion, ${ }^{1}$ Masoud Kamali, ${ }^{3,4}$ Melivin McInnis, ${ }^{3}$ Meihua R. Feng, ${ }^{1}$ Vicki Ellingrod, ${ }^{2}$ Andrew Babiskin, ${ }^{5}$ \\ Xinyuan Zhang, ${ }^{5}$ and Duxin Sun ${ }^{1,6}$
}

Received 25 January 2017; accepted 15 May 2017; published online 6 July 2017

Abstract. The purpose of this pharmacokinetics (PK) study was to investigate whether
different release kinetics from bupropion hydrochloride (HCl) immediate release (IR),
sustained release (SR), and extended release (ER) formulations alter its metabolism and to
test the hypothesis that the unsuccessful bioequivalence (BE) study of the higher strength
( $300 \mathrm{mg}$ ) of bupropion $\mathrm{HCl}$ ER tablets based on the successful BE study of the lower
strength ( $150 \mathrm{mg}$ ) was due to metabolic saturation in the gastrointestinal (GI) lumen. A
randomized six-way crossover study was conducted in healthy volunteers. During each
period, subjects took a single dose of IR ( $75 / 100 \mathrm{mg}$ ), SR (100/150 mg), or ER (150/300 mg)
formulations of bupropion HCl; plasma samples for PK analysis were collected from $0-96 \mathrm{~h}$
for all formulations. In addition, each subject's whole blood was collected for the genotyping
of various single-nucleotide polymorphisms (SNPs) of bupropion's major metabolic enzymes.
The data indicates that the relative bioavailability of the ER formulations was $72.3-78.8 \%$
compared with IR 75 mg. No differences were observed for ratio of the area under the curve
(AUC) of metabolite to AUC of parent for the three major metabolites. The
pharmacogenomics analysis suggested no statistically significant correlation between
polymorphisms and PK parameters of the various formulations. Altogether, these data
suggested that the different release kinetics of the formulations did not change metabolites-
to-parent ratio. Therefore, the differing BE result between the 150 and 300 mg bupropion
HCl ER tablets was unlikely due to the metabolic saturation in the GI lumen caused by
different release patterns.

KEY WORDS: bioequivalence; bupropion; carbonyl reductase; CYP2B6; metabolism.

"Andrew Babiskin and Xinyuan Zhang" Disclaimer: The views
expressed in this article are those of the authors and not necessarily
those of the Food and Drug Administration (FDA).

Electronic supplementary material The online version of this article (doi:10.1208/s12248-017-0102-8) contains supplementary material, which is available to authorized users.

${ }^{1}$ Department of Pharmaceutical Sciences, College of Pharmacy, University of Michigan, Ann Arbor, Michigan 48105, USA.

${ }^{2}$ Department of Clinical Pharmacy, University of Michigan, Ann Arbor, Michigan, USA.

${ }^{3}$ Prechter Bipolar Research Group, University of Michigan, Ann Arbor, Michigan, USA.

${ }^{4}$ Department of Psychiatry, Massachusetts General Hospital, Boston, Massachusetts, USA.

${ }^{5}$ Office of Research and Standards, Office of Generic Drugs, Food and Drug Administration, Silver Spring, Maryland, USA.

${ }^{6}$ To whom correspondence should be addressed. (e-mail: duxins@med.umich.edu)

\section{INTRODUCTION}

Bupropion hydrochloride $(\mathrm{HCl})$ is a clinically available drug product used for major depressive disorder, smoking cessation, and seasonal affective disorder (1). Bupropion was first marketed as an immediate release (IR) product in the 1980s for three times daily administration. In 1996 and 2003, a sustained release (SR) formulation (dosed twice a day) and extended release (ER) formulation (dosed once a day) became available, respectively, all utilizing the trade name of Wellbutrin (2).

Bupropion $\mathrm{HCl}$ is considered to be a biopharmaceutical classification system (BCS) class I drug (high permeability and high solubility) that exhibits linear pharmacokinetics (PK) in clinically available products (up to $450 \mathrm{mg}$ ) $(3,4)$. Bupropion $\mathrm{HCl}$ is rapidly absorbed; the $T_{\max }$ for an IR formulation is on the order of $1 \mathrm{~h}$, whereas the $T_{\max }$ for the SR and ER formulations are on the order of 3 and $5 \mathrm{~h}$, respectively (5). Bupropion $\mathrm{HCl}$ is extensively metabolized to form three active metabolites; hydroxybupropion and threo/erythrohydrobupropion (5). It is thought that these metabolites might exhibit potency up to 25- 
$50 \%$ of bupropion, as shown in an animal model $(6,7)$. In addition, hydroxybupropion and threohydrobupropion have been shown to have higher plasma concentrations than bupropion. A radiolabel study indicated that radioactive bupropion and metabolites are primarily eliminated in urine $(87 \%)$ and feces $(10 \%)$; however, only $0.05 \%$ of bupropion in urine is unchanged drug (8).

Bupropion is highly metabolized; Sager et al. highlight bupropion's metabolism based on current literature (9). CYP2B6 has been shown to be involved in the formation of hydroxybupropion. CYP2B6 polymorphic enzymes have been shown to exhibit as much as 20 to $250 \%$ differences in expression and activity (10). Furthermore, our recent study showed that bupropion is also metabolized by two major carbonyl reductases (11 $\beta$-dehydrogenase isozyme 1 in the liver and AKR7 in the intestine) to form threohydrobupropion and erythrohydrobupropion (11). Carbonyl reductase enzymes have also been found to be highly polymorphic (12-14). In addition, the expression of these enzymes changes through the gastrointestinal (GI) tract and liver $(10,15)$. Additionally, there is evidence that CYP2C19 and CYP3A4 may play a role in bupropion's metabolism $(9,16)$; however, these enzymes are less characterized compared to CYP2B6 and carbonyl reductase.

Prior to 2013, establishing bioequivalence (BE) for bupropion $\mathrm{HCl} 300 \mathrm{mg}$ ER tablets referencing Wellbutrin $\mathrm{XL}$ was based on acceptable in vivo BE study of the 150-mg strength, formulation proportionality, and similar dissolution profiles between the 150 - and $300-\mathrm{mg}$ strengths in multiple $\mathrm{pH}$ conditions. However, later on, it was reported that a generic of bupropion $\mathrm{HCl} 300 \mathrm{mg}$ ER tablet was not equivalent to the reference product (17). The purpose of this study was to investigate fundamental mechanisms that may cause the observed BE with the 150-mg strength and the lack of BE with the 300-mg strength, when these two strengths demonstrate formulation proportionality and similar in vitro dissolution profiles. The $T_{\max }$ disparity between the generic and reference products suggested different in vivo release patterns considering that bupropion is a BCS class 1 drug (17). Therefore, it was hypothesized that various SNP or the GI regional metabolic enzymes might interact differently with the $300 \mathrm{mg}$ tablets having different release patterns, which caused BE evaluation in the $150-\mathrm{mg}$ strength to fail to extrapolate up to the $300-\mathrm{mg}$ strength.

To address how different release kinetics of different formulations impact the PK and metabolism of bupropion, a randomized six-way crossover study of a single dose of bupropion $\mathrm{HCl}$ [IR (75 or $100 \mathrm{mg}$ ), SR (100 or $150 \mathrm{mg}$ ), or ER (150 or $300 \mathrm{mg}$ )] was conducted. Plasma PK samples were collected until $96 \mathrm{~h}$ for all formulations. Both bupropion and the major metabolites (hydroxybupropion, threohydrobupropion, and erythrohydrobupropion) were monitored by LC-MS/MS. In addition, pharmacogenomics was analyzed for CYP2B6, CYP2C19, and AKR7A3 and examined in relation to the PK of bupropion and its metabolites.

\section{METHODS}

\section{Study Population and Recruitment}

The study was posted on ClinicalTrials.gov with the registry number of NCT02078180. Both the informed consent and study protocol were approved by the Food and Drug Administration Institutional Review Board/Research Involving Human Subjects Committee (RIHSC, \#13-087D) and the University of Michigan Institutional Review Board (HUM00081894). In total, 33 subjects were recruited for this study and 30 completed the study (Table II). All subjects were voluntary, met the inclusion/ exclusion criteria, and provided informed consent prior to participation. All subjects were between the ages of 25 and 55 years old and had a body mass index between 18.5 and 35. Subjects were excluded if they had concomitant medical issues that would alter bupropion metabolism (liver disease, gastric bypass, etc.), nicotine dependence, and alcohol dependence or were either pregnant or nursing. Subjects were not excluded based on gender, race, or ethnicity.

\section{Study Design}

This study utilized a six-period, six-treatment crossover design under fasting conditions where each participant was administered a single dose of bupropion $\mathrm{HCl}$ IR $75 \mathrm{mg}$, IR $100 \mathrm{mg}$, SR $100 \mathrm{mg}$, SR $150 \mathrm{mg}$, ER 150, and ER $300 \mathrm{mg}$ tablet for each period. Prior to baseline, each participant fasted for at least $10 \mathrm{~h}$ pre-dosing and $4 \mathrm{~h}$ post-dosing. No water was given $1 \mathrm{~h}$ pre-dosing or post-dosing, with the exception of $240 \mathrm{~mL}$ of water that was taken with each pill. A minimum of a 10-day washout period occurred between each period. For sample collection, blood ( $~ 3$ to $4 \mathrm{~mL}$ ) was drawn at $0,0.5,1,2,3,4,6,8$ (12 h for ER tablets), 24, 48, 72, and 96 h.

\section{LC-MC/MS Method}

Whole blood was collected from all subjects and the actual time of sample collection was recorded and used for the data analysis. Whole blood was centrifuged at $15,000 \mathrm{rpm}$ at $4^{\circ} \mathrm{C}$. The supernatant (plasma) was collected and transferred to an EDTA $\mathrm{K} 2$ tube. Plasma samples were stored at $-80^{\circ} \mathrm{C}$.

The LC/MS/MS analysis was conducted using either an Agilent 1200 HPLC system coupled to an API 3200 mass spectrometer (Applied Biosystems, MDS Sciex Toronto, Canada) or Shimadzu HPLC coupled with an API4500 with an electrospray ionization (ESI) source. Quantitative analysis was accomplished on a Supelco C18 $(150 \times 4.6 \mathrm{~mm}$ I.D., $5 \mu \mathrm{m})$ column. The mobile phases were $0.04 \%$ formic acid in purified water (A) and $0.04 \%$ formic acid in methanol (B). The LC was ran either using isocratic at $35 \%$ methanol and the flow rate was set at $0.8 \mathrm{~mL} / \mathrm{min}$ on API3200, or with API4500, the LC separation started at $30 \% \mathrm{~B}$, maintained for $8 \mathrm{~min}$, then rose to $90 \% \mathrm{~B}$ and kept for 4 min, switched back to $30 \% \mathrm{~B}$ afterward, and kept for another $4 \mathrm{~min}$ with a flow rate of $1 \mathrm{~mL} / \mathrm{min}$.

The LC/MS/MS method was operated at positive ESI ionization mode. The multiple reaction monitoring (MRM) transitions and collision energies determined for bupropion, hydroxybupropion, threohydrobupropion, erythrohydrobupropion, and internal standard are listed in Table I. The analytical data were processed by Analyst software (versions 1.2 and 1.6; Applied Biosystems, Foster City, CA, USA).

The quantification of bupropion, hydroxybupropion, threohydrobupropion, and erythrohydrobupropion at different times and concentration were performed by MRM of the $[\mathrm{M}-\mathrm{H}]^{+}$ion, using venlafaxine as an internal standard (IS) to establish peak area ratios for calibration curve fitting. 
Table I. MRM Parameters for Bupropion, Hydroxybupropion, Threo/Erythrohydrobupropion, and IS Determination

\begin{tabular}{llclll}
\hline Compound name & MRM transition & $\begin{array}{l}\text { Collision } \\
\text { energy (CE) }\end{array}$ & $\begin{array}{l}\text { Declustering } \\
\text { potential (DP) }\end{array}$ & $\begin{array}{l}\text { Entrance } \\
\text { potential (EP) }\end{array}$ & $\begin{array}{l}\text { Collision cell exit } \\
\text { potential (CXP) }\end{array}$ \\
\hline Bupropion & $240.1 \rightarrow 184.0$ & $10(25)$ & $50(51)$ & 10 & $3(10)$ \\
Hydroxybupropion & $256.0 \rightarrow 238.0$ & $12(25)$ & $50(51)$ & 10 & $3(10)$ \\
Threo/erythrohydrobupropion & $242.0 \rightarrow 168.1$ & $5(25)$ & $50(51)$ & 10 & $3(10)$ \\
Venlafaxine (IS) & $278.0 \rightarrow 260.0$ & $10(25)$ & $50(51)$ & 10 & $3(10)$ \\
\hline
\end{tabular}

Some MS parameters used on the API4500 were different to ones used on the API3200. These parameters were indicated in the parentheses

\section{Method Validation}

The LC-MS/MS method was validated according to the FDA Bioanalytical Method Validation. The following test passed according to the guidance for bupropion and the three major metabolites: selectively, specificity, precision, matrix effect, recovery, carryover, standard curves, QC samples, short-term stability, and accuracy.

\section{Pharmacogenomic Analysis}

Selection of SNPs and Genotypes. The CYP2B6 polymorphisms, rs8192709 (variant allele present in $C Y P 2 B 6^{* 2}$ ), rs3745274 (variant allele present in $C Y P 2 B 6^{*} 6$ and $C Y P 2 B 6^{* 9}$ ), rs45482602 (variant allele present in $C Y P 2 B 6^{*} 3$ ), rs2279343 (variant allele present in CYP2B6*4 and CYP2B6*6), and rs3422 3104 (variant allele present in $C Y P 2 B 6^{* 22}$ ), were chosen based on previous reports suggesting that selected variants alter CYP2B6 activity $(16,18-22)$.
Selected polymorphisms for CYP2C19 genotyping, rs4986893 (variant allele present in $C Y P 2 C 19 * 3$ ), rs4244285 (variant allele present in $C Y P 2 C 19 * 2$ ), and rs12248560 (variant allele present in $C Y P 2 C 19^{*} 17$ ), were chosen based on their associations with drug metabolism (23-25).

Due to the small sample size of this investigation and paucity of literature pertaining to AKR7A3 and bupropion metabolism, $A K R 7 A 3$ polymorphisms, rs2231198, rs12405546, rs7525791, and rs2013249, were selected based a reported minor allele frequency (MAF) of at least 0.2 (www.1000genomes.org).

\section{Genotyping Methods}

A separate whole blood $(10 \mathrm{~mL})$ was collected from each subject and was used for genomic DNA extraction by

Table II. Subject Demographics and Baseline Lab Data

\begin{tabular}{lll}
\hline Variable & & Value \\
\hline $\begin{array}{l}\text { Demographics } \\
\text { Sex, } n(\%)\end{array}$ & Female & \\
& Male & $17(51.5 \%)$ \\
Ethnicity, $n(\%)$ & Hispanic & $16(48.5 \%)$ \\
& Non-Hispanic & $2(6.1 \%)$ \\
Race, $n(\%)$ & African American & $31(93.9 \%)$ \\
& Asian & $4(12.2 \%)$ \\
& Caucasian & $3(9.0 \%)$ \\
Patient characteristics, median (range) & Other & $24(72.7 \%)$ \\
Height $(\mathrm{cm})$ & & $2(6.1 \%)$ \\
Weight $(\mathrm{lb})$ & & $67.5(62.0,76.4)$ \\
BMI & & $176(124.2,236)$ \\
AST $(\mathrm{IU} / \mathrm{L})$ & & $25.9(20.6,36.0)$ \\
ALT $(\mathrm{IU} / \mathrm{L})$ & & $23(17,34)$ \\
WBC $\left(10^{3} / \mu \mathrm{L}\right)$ & & $23(13,40)$ \\
Hemoglobin $(\mathrm{g} / \mathrm{dL})$ & & $6.7(4.0,13.4)$ \\
HCT $(\%)$ & $14.2(11.9,17.8)$ \\
Platelet count $\left(10^{3} / \mu \mathrm{L}\right)$ & & $41.9(35.5,50.6)$ \\
BUN $(\mathrm{mg} / \mathrm{dL})$ & & $256(153,340)$ \\
HDL $(\mathrm{mg} / \mathrm{dL})$ & $14(8,26)$ & $8-30 \mathrm{IU} / \mathrm{L}$ \\
LDL $(\mathrm{mg} / \mathrm{dL})$ & $53(39,99)$ & $\leq 35 \mathrm{IU} / \mathrm{L}$ \\
\end{tabular}

The median (percent of population) is presented for each demographic and the median (range) patient characteristics

$B M I$ body mass index, $A S T$ aminotransferase blood test, $A L T$ alanine aminotransferase, $W B C$ white blood cell, $H C T$ hematocrit, $B U N$ blood urea nitrogen, $H D L$ high-density lipoprotein, $L D L$ low-density lipoprotein 
a
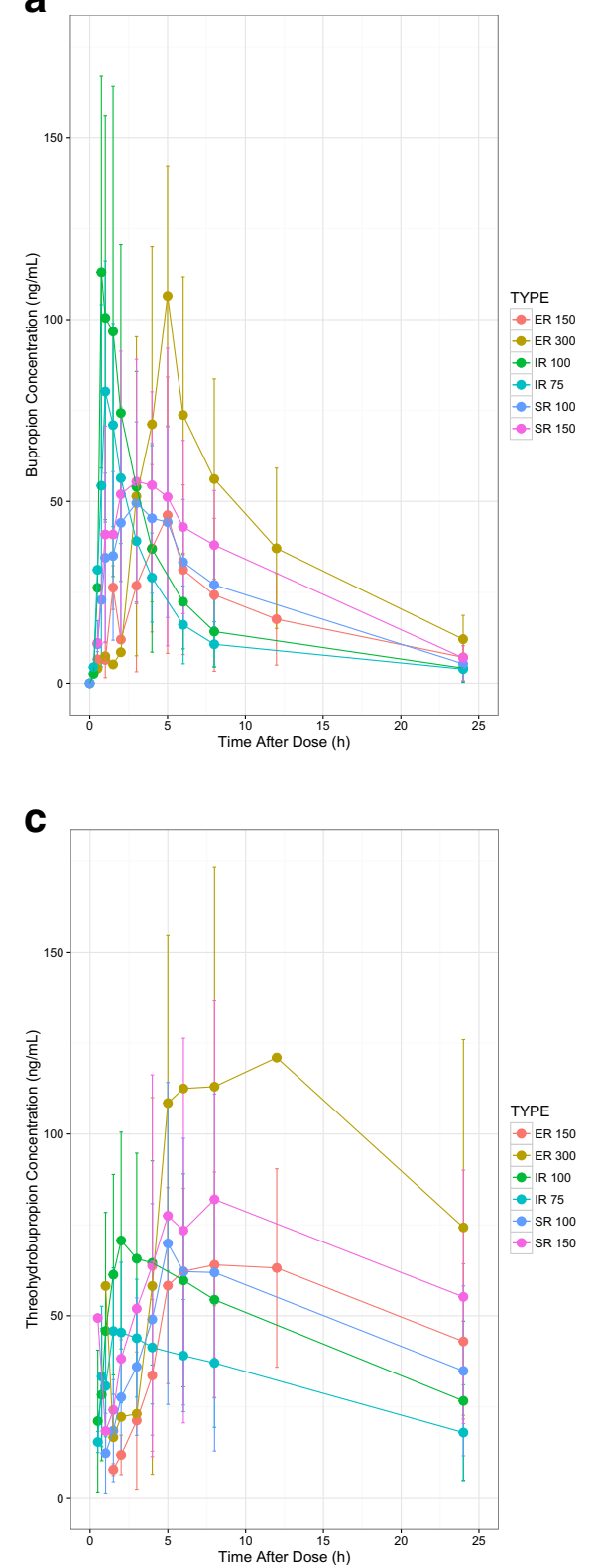

b

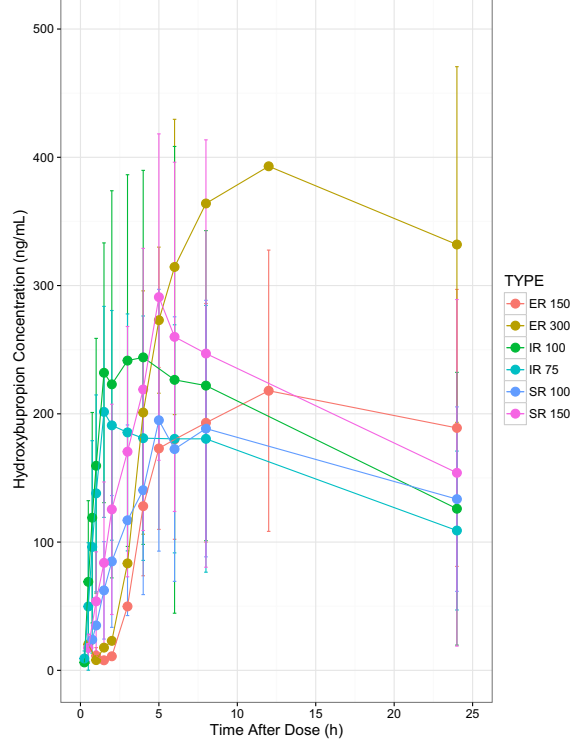

d

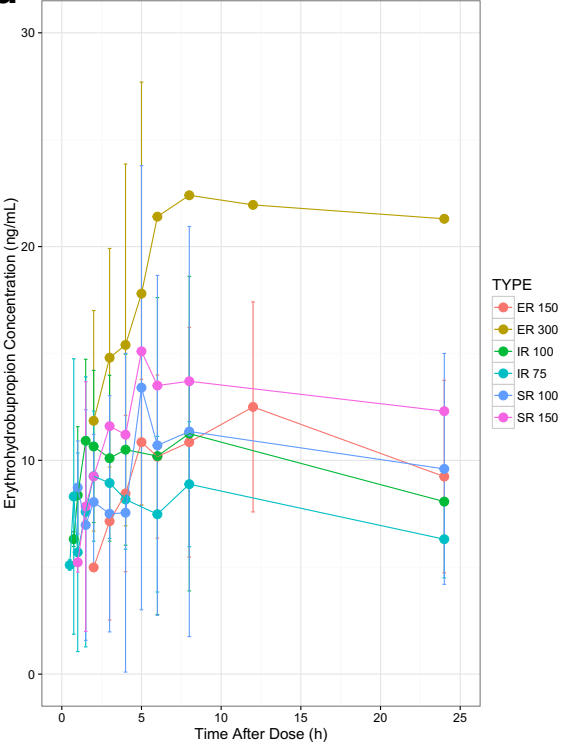

Fig. 1. Plasma concentration versus time profiles for bupropion and metabolites. The mean \pm standard deviation of the plasma concentration for bupropion and three major metabolites are represented for each formulation. a Bupropion. b Hydroxybupropion. c Threohydrobupropion. d Erythrohydrobupropion

the salt precipitation method as described previously (26). Genotyping was completed by polymerase chain reaction (PCR), followed by genotyping using Pyrosequencing ${ }^{\mathrm{TM}}$ technology (Qiagen, Hilden, Germany) for $C Y P 2 B 6$ and $A K R 7 A 3$ (27). PCR primers were designed using Pyrosequencing SNP Primer Design version 1.01 software (www.pyrosequencing.com). Assay conditions are available upon request. Genotyping for $C Y P 2 C 19$ was performed using the LightCycler ${ }^{\circledR} 480$ Instrument II (Roche Life Science, Indianapolis, IN) and TaqMan Genotyping Kits (Thermo Fisher Scientific Inc., Waltham, MA) by protocols designed by the manufacturer.

\section{Pharmacokinetic Parameter Estimates}

The parameters estimates were calculated using noncompartment analysis in Phoenix WINNONLIN (Pharsight, version 6.4.). The PK parameter estimates $\left(t_{1 / 2}, T_{\max }, C_{\max }\right.$, $\mathrm{AUC}_{0-\infty}, \mathrm{CL} / \mathrm{F}$, and $\left.V_{z} / F\right)$ were estimated from all individual concentration versus actual time profiles for each subject and all treatments of bupropion. The PK parameters $t_{1 / 2}, T_{\max }$, $C_{\max }$, and $\mathrm{AUC}_{0-\infty}$ were estimated for the major metabolites for each subject and all treatments. A minimum of three points excluding the $C_{\max }$ in the terminal phase was needed in order to calculate lambda, ${ }_{z}$ and associated PK parameters 
Table III. Relative Bioavailability of Bupropion

\begin{tabular}{lrll}
\hline & $\begin{array}{l}\text { AUC } \\
(\mathrm{h} \times \text { ng } \mathrm{ng} / \mathrm{mL})\end{array}$ & $\begin{array}{l}\text { Dose-normalized } \\
\mathrm{AUC}_{0 \text {-inf }}\end{array}$ & $\begin{array}{l}\text { Relative } \\
\text { bioavailability (\%) }\end{array}$ \\
\hline IR 75 & $469(38 \%)$ & $6.25 \pm 2.4$ & $100 \%$ \\
IR 100 & $688(62 \%)$ & $6.87 \pm 4.3$ & $110 \%$ \\
SR 100 & $706(43 \%)$ & $7.06 \pm 3.0$ & $113 \%$ \\
SR 150 & $1000(51 \%)$ & $6.68 \pm 3.4$ & $107 \%$ \\
ER 150 & $740(60 \%)$ & $4.93 \pm 2.9$ & $78.8 \%$ \\
ER 300 & $1360(47 \%)$ & $4.52 \pm 2.1$ & $72.3 \%$ \\
\hline
\end{tabular}

The $\mathrm{AUC}_{0 \text {-inf }}$ was calculated for each subject and formulation. The table shows the average $(\mathrm{CV} \%)$ and the dose-normalized $\mathrm{AUC}_{0 \text {-inf }}$ (mean \pm SD). The IR 75 formulation was used to calculate the relative bioavailability for each formulation

$\left(\mathrm{CL} / \mathrm{F}\right.$ and $\left.V_{z} / F\right)$. The mean \pm standard deviation is shown for each formulation.

\section{Population Pharmacokinetic Analysis}

The plasma concentrations versus actual time data were used for the data analysis. The population PK (PPK) analysis was performed using Nonlinear Mixed Effect Modeling Software, (NONMEM; version 7.3, Icon Development). The PPK structural model was fitted using both a one-compartment and two-compartment models. The model selection was based on the objective function value (OFV), shrinkage, goodness-of-fit plots, and standard error of the random effect parameters. The inter-individual variability (IIV) was described as an exponential error model and the residual variability (RV) was analyzed using the log error model. The IIV for the peripheral volume of distribution $\left(V_{3}\right)$ and blood flow $(Q)$ were fixed.

For the covariate analysis, the SNPs for the three metabolism enzymes were added as covariates to the $\mathrm{CL} / \mathrm{F}$ and $V / F$ terms linearly. Covariates were grouped in the model based on suggested SNP variant (i.e., homozygous dominant, heterozygous, and homozygous recessive). In addition, CYP2B6 was also further explored using the suggested phenotype for each individual. Covariates were selected if they had a minimum $p$ value $<0.05$ ( $\triangle \mathrm{OFV} \leq 3.84)$ in the forward selection and $p$ value of $<0.001(\Delta \mathrm{OFV} \leq 10.83)$ in the backward method. Covariates that were selected were validated by performing bootstrap and visual predictive check (VPC).

\section{Data Analysis}

Data were graphically analyzed using R (version 3.2.4).

\section{RESULTS}

\section{Subject Randomization}

A total of 33 subjects were enrolled in the study and 30 completed all 6 periods for data analysis. Each subject received a single dose of bupropion $\mathrm{HCl}$ tablets (IR 75 or $100 \mathrm{mg}$, SR 100 or $150 \mathrm{mg}$, or ER 150 or $300 \mathrm{mg}$ ) during each period.

The demographic and baseline lab data collected for the study are summarized in Table II. The study population was almost half females and half males (16 males and 17 females) and most subjects were Caucasian $(72.7 \%)$.

Table IV. Bupropion PK Parameters

\begin{tabular}{|c|c|c|c|c|c|c|c|c|}
\hline \multicolumn{9}{|c|}{$(\mathrm{A}$} \\
\hline & & $n$ & $C_{\max }(\mathrm{ng} / \mathrm{mL})$ & $T_{\max }(\mathrm{h})$ & $t_{1 / 2}(\mathrm{~h})$ & $\operatorname{AUC}_{0-\infty}(\mathrm{ng} \times \mathrm{h} / \mathrm{mL})$ & $\mathrm{CL} / \mathrm{F}(\mathrm{L} / \mathrm{h})$ & $V_{z} / F(\mathrm{~L})$ \\
\hline \multirow[t]{6}{*}{ Bupropion } & IR 75 & 30 & $93 \pm 36$ & $1.3 \pm 1.1$ & $10 \pm 6$ & $469 \pm 177$ & $182 \pm 68$ & $2420 \pm 1330$ \\
\hline & IR 100 & 32 & $134 \pm 70$ & $1.2 \pm 0.7$ & $10 \pm 8$ & $688 \pm 427$ & $181.2 \pm 81$ & $2110 \pm 800$ \\
\hline & SR 100 & 30 & $61 \pm 29$ & $2.9 \pm 1.5$ & $12 \pm 11$ & $706 \pm 304$ & $169 \pm 68$ & $2250 \pm 1600$ \\
\hline & SR 150 & 32 & $78 \pm 40$ & $3.2 \pm 1.9$ & $12 \pm 9$ & $1002 \pm 516$ & $188 \pm 132$ & $3460 \pm 1380$ \\
\hline & ER 150 & 30 & $61 \pm 34$ & $4.7 \pm 1.3$ & $15 \pm 16$ & $740 \pm 449$ & $289 \pm 181$ & $4110 \pm 2280$ \\
\hline & ER 300 & 30 & $111 \pm 44$ & $4.8 \pm 1.8$ & $14 \pm 9$ & $1356 \pm 637$ & $282 \pm 136$ & $4570 \pm 2170$ \\
\hline \multicolumn{9}{|l|}{ (B) } \\
\hline & Paramete & & & Units & Base mc & 1 estimate (SE) & Shrinkage & \\
\hline \multirow[t]{7}{*}{ Fixed effects } & SR-F & & & & $0.96(0.0$ & & $19.5 \%$ & \\
\hline & ER-F & & & & $0.68(0.0$ & & $43.9 \%$ & \\
\hline & $K_{a}$ & & & $1 / \mathrm{h}$ & $0.47(0.0$ & & n.a. & \\
\hline & $\mathrm{CL}$ & & & $\mathrm{L} / \mathrm{h}$ & $154(68$ & & n.a. & \\
\hline & $V_{2}$ & & & $\mathrm{~L}$ & $1070(30$ & & $20.7 \%$ & \\
\hline & $V_{3}$ & & & $\mathrm{~L}$ & 2530 & & & \\
\hline & $Q$ & & & $\mathrm{~L} / \mathrm{h}$ & $103(7.2$ & & & \\
\hline \multirow[t]{3}{*}{ IIV } & $K_{a}$ & & & $\%$ & $96.0 \%$ & $8 \%)$ & & \\
\hline & $\mathrm{CL}$ & & & $\%$ & $33.6 \%$ & $1 \%)$ & & \\
\hline & $V_{2}$ & & & $\%$ & $47.4 \%$ & $8 \%)$ & & \\
\hline Residual variability & Proportio & & & $\%$ & $54.7 \%$ & $6 \%)$ & & \\
\hline
\end{tabular}

PK parameters were estimated by non-compartment analysis (A). The mean \pm standard deviation (SD) is shown for each parameter. The population pharmacokinetic model for bupropion was fitted to a two-compartment model (B). The structure model is shown for the fixed and random effects

$n$ number of subjects, $C_{\max }$ time to maximum concentrations, $T_{\max }$ time to $C_{\max }, t_{1 / 2}$ half life, $A U C_{0-\infty}$ area under the time versus concentration plot from 0 to infinity, $C L / F$ apparent clearance, $V_{z} / F$ apparent volume of distribution, $S E$ standard error, $F$ relative bioavailability (referenced to IR formulation), $I I V$ inter-individual variability, $K_{a}$ absorption rate constant, $V_{2}$ central volume of distribution, $V_{3}$ peripheral volume of distribution, $C L$ clearance, $Q$ blood flow 
Table V. PK Parameters for Metabolites

\begin{tabular}{llllcccc}
\hline & & $n$ & $C_{\max }(\mathrm{ng} / \mathrm{mL})$ & $T_{\max }(\mathrm{h})$ & $t_{1 / 2}(\mathrm{~h})$ & $\mathrm{AUC}_{0-\infty}(\mathrm{ng} \times \mathrm{h} / \mathrm{mL})$ & Dose-normalized AUC \\
\hline Hydroxybupropion & IR 75 & 30 & $232 \pm 105$ & $4.8 \pm 4.1$ & $23.3 \pm 9.2$ & $9,020 \pm 5,080$ & $120 \pm 68$ \\
& IR 100 & 32 & $296 \pm 154$ & $3.4 \pm 1.4$ & $22.7 \pm 6.6$ & $10,800 \pm 7,000$ & $108 \pm 70$ \\
& SR 100 & 30 & $223 \pm 99$ & $7.3 \pm 3.5$ & $24.0 \pm 8.4$ & $10,100 \pm 6,010$ & $101 \pm 60$ \\
& SR 150 & 32 & $311 \pm 168$ & $6.4 \pm 1.3$ & $23.4 \pm 8.1$ & $14,300 \pm 9,700$ & $95.2 \pm 64.9$ \\
& ER 150 & 30 & $242 \pm 110$ & $12.2 \pm 6.0$ & $24.9 \pm 6.7$ & $12,100 \pm 8,000$ & $80.5 \pm 53.1$ \\
& ER 300 & 32 & $402 \pm 145$ & $10.0 \pm 4.7$ & $23.5 \pm 8.0$ & $19,700 \pm 9,700$ & $65.7 \pm 32.4$ \\
Threohydrobupropion & IR 75 & 30 & $53.9 \pm 17.9$ & $3.1 \pm 1.7$ & $35.3 \pm 18.5$ & $2,050 \pm 990$ & $27.3 \pm 13.2$ \\
& IR 100 & 32 & $85.5 \pm 30.9$ & $3.1 \pm 1.8$ & $39.5 \pm 15.6$ & $3,260 \pm 1,950$ & $32.6 \pm 19.5$ \\
& SR 100 & 30 & $67.9 \pm 32.6$ & $6.8 \pm 3.6$ & $41.4 \pm 11.3$ & $3,300 \pm 1,600$ & $33.0 \pm 16.0$ \\
& SR 150 & 32 & $104 \pm 64$ & $6.5 \pm 1.5$ & $44.7 \pm 44.1$ & $4,880 \pm 2,170$ & $32.5 \pm 14.8$ \\
& ER 150 & 30 & $70.9 \pm 28.5$ & $8.4 \pm 4.3$ & $41.7 \pm 14.4$ & $3,860 \pm 1,720$ & $25.7 \pm 11.5$ \\
& ER 300 & 30 & $144 \pm 71$ & $9.2 \pm 4.7$ & $42.2 \pm 14.3$ & $7,350 \pm 4,740$ & $24.5 \pm 15.8$ \\
Erythrohydrobupropion & IR 75 & 30 & $8.5 \pm 5.9$ & $4.2 \pm 2.2^{a}$ & $26.9 \pm 18.3^{b}$ & $439 \pm 303^{\mathrm{b}}$ & $5.8 \pm 4.0$ \\
& IR 100 & 32 & $13.6 \pm 8.0$ & $5.0 \pm 4.0^{c}$ & $46.0 \pm 63.8^{d}$ & $1,020 \pm 1,240^{d}$ & $10.2 \pm 12.4$ \\
& SR 100 & 30 & $11.0 \pm 6.4$ & $8.0 \pm 5.3^{e}$ & $38.4 \pm 17.3^{f}$ & $774 \pm 369^{\mathrm{f}}$ & $7.7 \pm 3.7$ \\
& SR 150 & 32 & $15.2 \pm 6.5$ & $9.6 \pm 9.0$ & $60.0 \pm 95.5^{g}$ & $1,510 \pm 2,060^{g}$ & $10.0 \pm 13.7$ \\
& ER 150 & 22 & $13.8 \pm 4.8$ & $12.4 \pm 9.5$ & $31.0 \pm 14.7^{h}$ & $765 \pm 432^{h}$ & $5.1 \pm 2.9$ \\
& ER 300 & 32 & $24.8 \pm 10.6$ & $10.3 \pm 6.1$ & $43.3 \pm 37.2^{i}$ & $1,860 \pm 1,480^{i}$ & $6.2 \pm 4.9$ \\
\hline
\end{tabular}

The PK parameters were estimated by non-compartment analysis. The mean \pm standard deviation (SD) is shown for each parameter. Number of subjects for parameter estimates may have been adjusted based on the data available

$n$ number of subjects, $C_{\max }$ time to maximum concentrations, $T_{\max }$ time to $C_{\max }, t_{1 / 2}$ half life, $A U C_{0-\infty}$ area under the time versus concentration plot from 0 to infinity

${ }^{a} n=24$

${ }^{b} n=10$

${ }^{c} n=30$

${ }^{d} n=20$

${ }^{e} n=25$

${ }^{f_{n}}=13$

${ }^{g} n=18$

${ }^{h} n=14$

${ }^{i} n=27$

All adverse events (AEs) were summarized in Supplemental Table I. All AEs were mild to moderate; of the 11 AEs reported from 7 subjects, the most common adverse events reported were headaches, fatigue, or nausea $(n=8)$. In addition, these AEs may be due to study conditions rather than investigational products (i.e., no caffeine, 10-h fasting).

Table VI. Allele Frequencies of $C Y P 2 B 6, C Y P 2 C 19$, and $A K R 7 A 3$

\begin{tabular}{|c|c|c|c|c|c|}
\hline Gene & SNP & AA & Variant & Reference sequence identification & Observed frequencies \\
\hline \multicolumn{6}{|c|}{ CYP2B6 } \\
\hline & $\mathrm{T}-82 \mathrm{C}$ & & $* 22$ & rs34223104 genotype, TT/TC/CC & $33 / 0 / 0$ \\
\hline & $\mathrm{C} 64 \mathrm{~T}$ & $\mathrm{R} 22 \mathrm{C}$ & $* 2$ & rs8192709 genotype, CC/CT/TT & $30 / 3 / 0$ \\
\hline & G516T & Q172H & $* 6, * 7, * 9$ & rs3745274 genotype, GG/GT/TT & $0 / 26 / 7$ \\
\hline & C777A & S259R & $* 5$ & rs45482602 genotype, CC/CA/AA & $33 / 0 / 0$ \\
\hline & A785G & $\mathrm{K} 262 \mathrm{R}$ & $* 4, * 5, * 6$ & rs2279343 genotype, AA/AG/GG & $7 / 25 / 1$ \\
\hline \multicolumn{6}{|c|}{ CYP2C19 } \\
\hline & G22948A & W212Ter & $* 3$ & rs4986893 genotype, GG/GA/AA & $33 / 0 / 0$ \\
\hline & G681A & $\mathrm{P} 227 \mathrm{P}$ & $* 2$ & rs4244285 genotype, GG/GA/AA & $27 / 4 / 0^{a}$ \\
\hline & C-806T & & $* 17$ & rs12248560 genotype, CC/CT/TT & $21 / 9 / 2^{a}$ \\
\hline \multicolumn{6}{|c|}{$A K R 7 A 3$} \\
\hline & G489A & V138M & & rs2231198 genotype, GG/GA/AA & $10 / 23 / 0$ \\
\hline & $\mathrm{A} 215-546 \mathrm{G}$ & & & rs12405546 genotype, AA/AG/GG & $21 / 9 / 3$ \\
\hline & $\mathrm{G} 215-697 \mathrm{~A}$ & & & rs7525791 genotype, GG/AG/AA & $4 / 20 / 9$ \\
\hline & $\mathrm{C} 214+926 \mathrm{G}$ & & & rs2013249 genotype, CC/CG/GG & $5 / 28 / 0$ \\
\hline
\end{tabular}

Each subject was genotyped for selected SNPs in (a) CYP2B6, (b) $C Y P 2 C 19$, and (c) $A K R 7 A 3$. The amino acid (AA) substitution, SNP, and rs number designations are displayed

Ter termination

${ }^{a}$ One subject's genotype was undetermined 


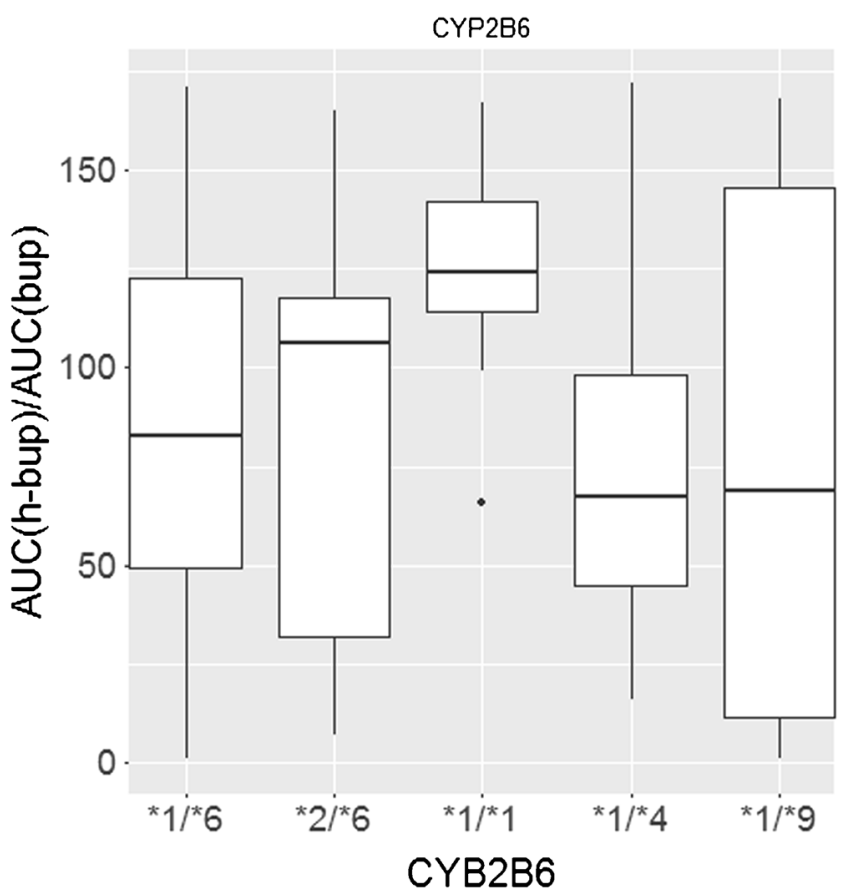

Fig. 2. Ratio of $\operatorname{AUC}(\mathrm{m}) / \mathrm{AUC}(\mathrm{p})$ for hydroxybupropion. The AUC(hydroxybupropion)/AUC(bupropion) is shown for CYP2B6 variants. The solid black line represents the median. The height of each box corresponds to the interval between the first and the third quartiles, and the bar represents 1.5 times the interquartile range

\section{Bupropion and Major Metabolite Concentrations}

The mean plasma concentration versus time profiles for bupropion and the major metabolites by formulation at different dose levels are represented in Fig. 1. Hydroxybupropion and threohydrobupropion showed higher plasma concentrations compared to bupropion, with hydroxybupropion mean concentration nearly fivefold higher than bupropion. Erythrohydrobupropion formation was minor, and in some subjects, erythrohydrobupropion was not even detected.

The relative bioavailability of bupropion was examined (Table III). The mean $\mathrm{AUC}_{0 \text {-inf }}(\% \mathrm{CV})$ associated with each formulation was calculated. There was a moderately large intersubject variability observed within each formulation. The mean dose-normalized AUC was also calculated to compare exposure among formulations. The mean AUC of IR $75 \mathrm{mg}$ formulation was used as a reference to calculate the relative bioavailability. For the IR and SR formulations, the mean relative bioavailability was similar (100-113\%). However, for the ER formulation, the mean bioavailability was more than $20 \%$ less compared to the $75 \mathrm{mg}$ of the IR formulation. This suggested that for the ER formulation, either less bupropion was getting into the systemic circulation or more bupropion was being metabolized.

The PK parameters of bupropion and the metabolites were estimated from a non-compartmental analysis for each subject and formulation. The mean $\pm \mathrm{SD}$ for each formulation for bupropion is shown in Table IV (A). The apparent clearance $(\mathrm{CL} / \mathrm{F})$ and volume of distribution $\left(V_{z} / F\right)$ for all the formulations were 169 to $288.5 \mathrm{~L} / \mathrm{h}$ and 2109.5 to $4564.6 \mathrm{~L}$. The IR and $\mathrm{SR}$ formulations $\mathrm{CL} / \mathrm{F}$ and $V_{z} / F$ were relatively similar; however, the ER formulation showed higher $\mathrm{CL} / \mathrm{F}$ and $V_{z} / F$. The half-life was consistent among formulations, ranging from
10 to $14 \mathrm{~h}$. The $T_{\max }$ was consistent with previous literature for each formulation with the IR, SR, and ER formulations showing $\sim 1,3$, and $5 \mathrm{~h}$, respectively (5).

Major metabolite PK parameters are shown in Table V. For erythrohydrobupropion, many subjects' PK parameters were not estimated due to lack of formation or not enough points in the terminal phase to estimate the half-life and $\mathrm{AUC}_{0-\infty}$. For hydroxybupropion and threohydrobupropion, the $T_{\max }$ formed consistent with bupropion's formulation, where the IR, SR, and ER formulations were approximately 3-4, 6-7, and 10-12 h, respectively. The mean dose-normalized AUC decreased slightly for hydroxybupropion for the ER formulations, but this decrease is likely not significant. For threohydrobupropion and erythrohydrobupropion, there was practically no difference in dose-normalized concentrations among the various formulations.

Bupropion plasma concentrations and time data from all formulations were used for this analysis. Both a onecompartment model and two-compartment model were fitted to determine the optimum structure model. The twocompartment model described the data best. In addition to the objective function value (OFV) for model evaluation, goodnessof-fit plots, shrinkage, and standard errors were evaluated to confirm the two-compartment model (data not shown). The relative bioavailability $(F)$ was calculated using the IR formulation as a reference (IR $F=1$ ). The relative bioavailability estimated for the SR formulation was $95.5 \%$ and for the ER formulation was $68 \%$. Both peripheral volume of distribution $\left(V_{3} / F\right)$ and blood flow $(Q)$ inter-individual variability (IIV) was fixed in the two-compartment model. The model showed that the typical clearance value was $154 \mathrm{~L} / \mathrm{h}$ and the typical central volume of distribution was $1070 \mathrm{~L}$ for this population (Table IV (B)). The IIV for the absorption constant was high, likely due to the various formulations included in the model.

\section{Pharmacogenomic Analysis}

Genes encoding bupropion-metabolizing enzymes, $C Y P 2 B 6, C Y P 2 C 19$, and $A R K 7 A 3$, were genotyped for the selected polymorphisms (Table VI). There were several SNPs in our population that had no variability and therefore were excluded from the individual SNP analysis (rs34223104, rs45482602, and rs4986893). PK measurements were then evaluated to determine the impact of each polymorphism on clearance or volume of distribution. Polymorphisms that showed zero variability in our subject cohort were excluded from our PK analysis. The covariate model was run in the forward method selection at a $p<0.05$ and in the backward method of $p<0.001$. However, no polymorphisms were statistically significant, suggesting that either pharmacogenomics had no impact on PK or our sample size was too small to measure the impact of these polymorphisms on bupropion metabolism.

To further confirm that these SNPs had no effect on PK in our cohort, the $\mathrm{AUC}(\mathrm{m}) / \mathrm{AUC}(\mathrm{p})$ ratio was calculated for each variant corresponding to the metabolite it produces (Figs. 2 and $3)$. Figure 2 shows the $\mathrm{AUC}(\mathrm{m}) / \mathrm{AUC}(\mathrm{p})$ of hydroxybupropion to bupropion grouped by $C Y P 2 B 6$ and $C Y P 2 C 19$ variant alleles. We found that CYP2B6 was not associated with variability in the ratio of AUC (hydroxybupropion)/AUC (bupropion). Figure 3 shows the $\operatorname{AUC}(\mathrm{m}) / \mathrm{AUC}(\mathrm{p})$ of threohydrobupropion to bupropion for AKR7A3 (Fig. 3a-d) and CYP2C19 (Fig. 3e, f). No differences were observed for the 
a

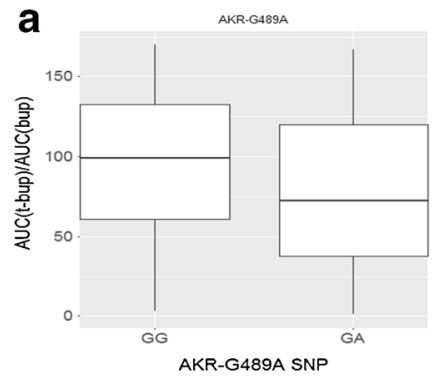

C

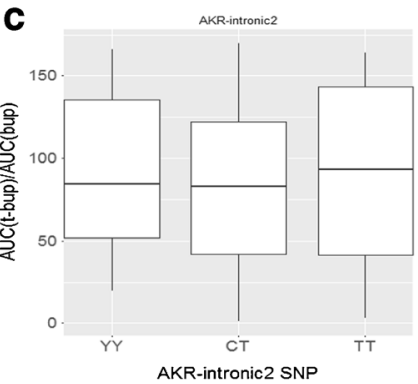

e

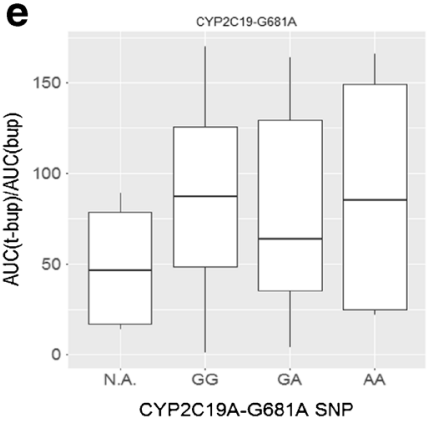

b

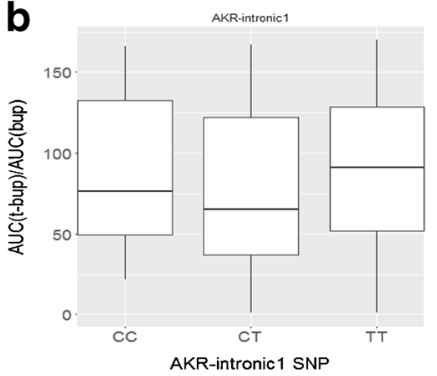

d

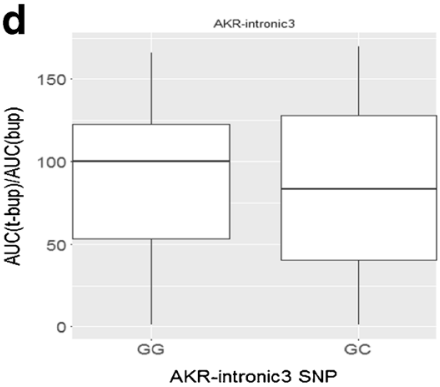

f

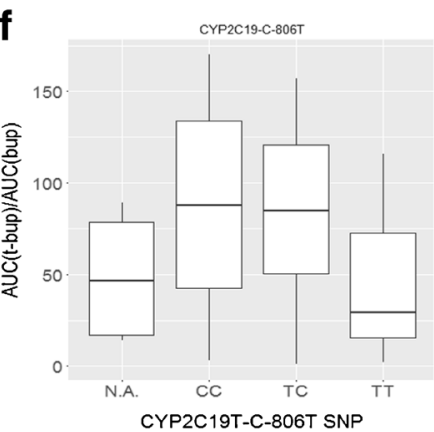

Fig. 3. Ratio of $\mathrm{AUC}(\mathrm{m}) / \mathrm{AUC}(\mathrm{p})$ for threohydrobupropion. The AUC(threohydrobupropion)/AUC(bupropion) is shown for AKR7A family a AKR7-G489A, b intronic 1, c intronic 2, and $\mathbf{d}$ intronic3. In addition, CYP2C19 e CYP2C19A-G681A phenotype and f CYP2C19T-C-806T phenotype. The height of each box corresponds to the interval between the first and the third quartiles, and the bar represents 1.5 times the interquartile range. $N . A$. not available

ratio of AUC (threohydrobupropion)/AUC (bupropion) for any variant allele. Similar results were observed for erythrohydrobupropion (data not shown, due to the low systemic concentrations).

\section{Regional GI Metabolism Analysis}

To further evaluate whether formulations could have regional GI metabolism rather than genetic metabolism differences, the ratio of the $\mathrm{AUC}(\mathrm{m})$ to that time point over the ratio of the AUC(p) was plotted for each formulation for all three metabolites (Fig. 4). For hydroxybupropion, there was no statistically significant difference among formulation for the $\operatorname{AUC}(\mathrm{m}) / \mathrm{AUC}(\mathrm{p})$ ratio, indicating that the higher exposure of hydroxybupropion was not formulation dependent. Likewise, this was also observed for threohydrobupropion and erythrohydrobupropion. For all three metabolites, there was no observable trend. For the modified release (SR and ER) products, a longer exposure to the GI tract may allow more metabolism to occur through GI metabolic enzymes. Therefore, one would expect to see higher ratio of $\mathrm{AUC}(\mathrm{m}) / \mathrm{AUC}(\mathrm{p})$ if this phenomenon was occurring. Since higher metabolite ratios were not observed for any of the three major metabolites, these data suggested that there was no difference in regional GI metabolism occurring with different formulations.

\section{DISCUSSION}

In this study, a total of 30 genotyped subjects completed all 6 periods. The ER formulation showed a lower relative bioavailability when compared to the IR formulation. The data suggest that the concentrations of bupropion and the major metabolites are variable, yet there is no significant difference between the ratio of $\mathrm{AUC}(\mathrm{m}) / \mathrm{AUC}(\mathrm{p})$ for all three major metabolites in any formulations. Population analysis was performed to analyze for differences in SNP and concentration, yet no statistically significant SNP was found to address concentration differences for bupropion or its metabolites.

This investigation critically analyzed bupropion $\mathrm{HCl}$ metabolites using various formulations. Since bupropion is 

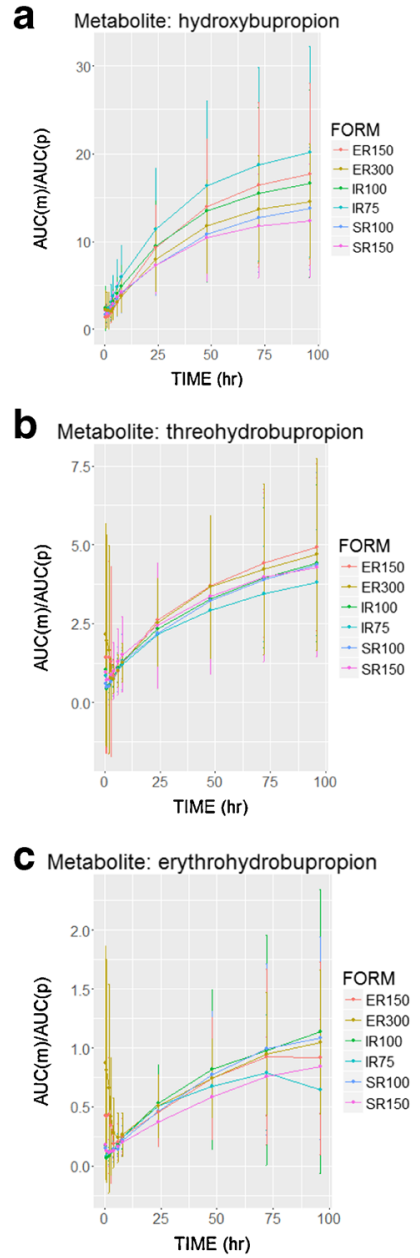

Fig. 4. Ratio of $\operatorname{AUC}(m) / A U C(p)$. The mean \pm standard deviation of the ratio of AUC between each metabolite a hydroxybupropion, b threohydrobupropion, and $\mathbf{c}$ erythrohydrobupropion, and bupropion is shown over time for each formulation

extensively metabolized to form three major active metabolites both in the gut and liver, it was hypothesized that variations in metabolism of formulations with different GI release pattern may account for differences in PK. In addition, full pharmacogenomics were completed for these 30 subjects for ARK7A3, CYP2B6, and CYP2C19. Recent studies have suggested that CYP2C19 is important in vivo for bupropion's PK (16). For the modified release (MR) products, a longer exposure to the GI tract may allow more metabolism to occur through GI metabolic enzymes. Therefore, one would expect to see higher ratio of $\mathrm{AUC}(\mathrm{m}) / \mathrm{AUC}(\mathrm{p})$ if this phenomenon was occurring.

It was observed that the dose-normalized systemic exposure decreased for the ER formulation compared to the IR formulation. It is unknown whether this decrease is due to late release in the GI tract and therefore lack of absorption or whether there was a lack of release and the drug was excreted in the feces. As part of this investigation, we found little contribution of bupropion PK to the described polymorphisms in $A R K 7 A 3, C Y P 2 B 6$, and $C Y P 2 C 19$. Previous work suggests a role for $\mathrm{CYP} 2 \mathrm{~B} 6$ and $\mathrm{CYP} 2 \mathrm{C} 19$ in bupropion metabolism. CYP2B6 is known to metabolize bupropion into the pharmacologically active metabolite hydroxybupropion (28). While increased levels of hydroxybupropion are linked to clinical benefits such as increased success of smoking cessation, CYP2B6 is not associated with plasma levels of the parent drug suggesting that alternate mechanisms of metabolism are important (18). The most common $C Y P 2 B 6$ variant in population studies and in our cohort is $C Y P 2 B 6^{*} 6$. This variant results in lower amounts of functional $C Y P 2 B 6$ mRNA and, therefore, decreased enzymatic activity (29), which affects hydroxybuproprion AUC. Likewise, the variant CYP2C19*2, also a reduced activity allele, is associated with increased AUC of bupropion and its metabolites threohydrobupropion and erythrohydrobupropion (16). Unlike what is observed in the literature, we did not observe any PK differences associated with our genotyping analysis. Altogether, the PK analysis and graphical analysis suggest that genetic differences play little involvement in bupropion's metabolism in our cohort. A limitation to our analysis is a small study size, which may mask the contribution of pharmacogenetics to bupropion metabolism.

Likewise, various formulations were compared for the ratio of $\operatorname{AUC}(\mathrm{m}) / \mathrm{AUC}(\mathrm{p})$ for each metabolite. None of the three major metabolites showed a statistically significant difference in ratio nor trend, suggesting that GI regional metabolism was not causing the differences as well. Our previous in vitro metabolism study suggested that threohydrobupropion could be formed by intestinal carbonyl reductase (19). The plasma concentration data of parents and metabolites lumped the processes of intestinal metabolism, intestinal absorption, and liver metabolism. In order to have better insight of the metabolism in the GI tract, a mechanism-based absorption model that incorporated the gut metabolism, absorption, and liver metabolism could be helpful to understand the GI regional metabolism of different bupropion $\mathrm{HCl}$ formulations at different dose levels.

In the case of the two different strength BE studies conducted with generic bupropion $\mathrm{HCl}$ tablets against Wellbutrin XL, the establishment of BE with the lower strength (150 mg) and the failure to meet BE standards for the higher strength $(300 \mathrm{mg})$ is not due to metabolic saturation in the GI lumen because there was no statistically significant difference in ratios of $\mathrm{AUC}(\mathrm{m}) / \mathrm{AUC}(\mathrm{p})$ among different formulations (Fig. 4). Other factors may have contributed to the unsuccessful BE study of the higher-strength $(300 \mathrm{mg})$ bupropion $\mathrm{HCl}$ ER tablets.

The issue of whether monitoring metabolites in BE studies have been debated for quite some time (30-33). Our results suggest that GI metabolism does not clinically contribute to variation or decrease relative bioavailability. Instead, we observed that the release profile, lower absorption later in the GI track, or lack of release is the most significant contributor to relative bioavailability. These results also suggest that the reason for the BE failure at the $300 \mathrm{mg}$ ER formulation was not due to metabolism. This is consistent with the pilot study performed by the FDA using Wellbutrin and Budeprion (failed BE generic drug product), where in the Budeprion arm, both bupropion and two of the three metabolites (hydroxybupropion and threohydroupropion) showed lower systemic exposure compared to the brand name drug product (34).

From this study, in combination with our previous findings (16), it is very unlikely that the establishment of BE with the lower strength $(150 \mathrm{mg})$ and the failure to meet BE standards for the higher strength $(300 \mathrm{mg})$ was due to metabolic saturation in the GI lumen. Additional research, including modeling and 
simulation efforts, will be needed to investigate the root cause for the failure to meet $\mathrm{BE}$ standards for the higher strength based on a BE study on a lower strength.

\section{ACKNOWLEDGEMENTS}

We would like to thank the Food and Drug Administration (contract number HHSF223201310164C) for the funding support.

Open Access This article is distributed under the terms of the Creative Commons Attribution 4.0 International License (http://creativecommons.org/licenses/by/4.0/), which permits unrestricted use, distribution, and reproduction in any medium, provided you give appropriate credit to the original author(s) and the source, provide a link to the Creative Commons license, and indicate if changes were made.

\section{REFERENCES}

1. Fava M, Rush AJ, Thase ME, Clayton A, Stahl SM, Pradko JF, et al. 15 years of clinical experience with bupropion $\mathrm{HCl}$ : from bupropion to bupropion SR to bupropion XL. Prim Care Companion J Clin Psychiatry. 2005;7(3):106-13.

2. Dhillon S, Yang LP, Curran MP. Spotlight on bupropion in major depressive disorder. CNS Drugs. 2008;22(7):613-7.

3. Daviss WB, Perel JM, Rudolph GR, Axelson DA, Gilchrist R, Nuss S, et al. Steady-state pharmacokinetics of bupropion SR in juvenile patients. J Am Acad Child Adolesc Psychiatry. 2005;44(4):349-57.

4. Foley KF, DeSanty KP, Kast RE. Bupropion: pharmacology and therapeutic applications. Expert Rev Neurother. 2006;6(9):1249-65.

5. Jefferson JW, Pradko JF, Muir KT. Bupropion for major depressive disorder: pharmacokinetic and formulation considerations. Clin Ther. 2005;27(11):1685-95.

6. Bondarev ML, Bondareva TS, Young R, Glennon RA. Behavioral and biochemical investigations of bupropion metabolites. Eur J Pharmacol. 2003;474(1):85-93.

7. Damaj MI, Carroll FI, Eaton JB, Navarro HA, Blough BE, Mirza S, et al. Enantioselective effects of hydroxy metabolites of bupropion on behavior and on function of monoamine transporters and nicotinic receptors. Mol Pharmacol. 2004;66(3):675-82.

8. Findlay JW, Van Wyck FJ, Smith PG, Butz RF, Hinton ML, Blum MR, et al. Pharmacokinetics of bupropion, a novel antidepressant agent, following oral administration to healthy subjects. Eur J Clin Pharmacol. 1981;21(2):127-35.

9. Sager JE, Price LS, Isoherranen N. Stereoselective metabolism of bupropion to OH-bupropion, threohydrobupropion, erythrohydrobupropion, and $4^{\prime}-\mathrm{OH}$-bupropion in vitro. Drug Metab Dispos. 2016;44(10):1709-19.

10. Wang H, Tompkins LM. CYP2B6: new insights into a historically overlooked cytochrome P450 isozyme. Curr Drug Metab. 2008;9(7):598-610.

11. Connarn JN, Luo R, Windak J, Zhang X, Babiskin A, Kelly M, et al. Identification of non-reported bupropion metabolites in human plasma. Biopharm Drug Dispos. 2016;37(9):550-60.

12. Oppermann UC, Maser E. Molecular and structural aspects of xenobiotic carbonyl metabolizing enzymes. Role of reductases and dehydrogenases in xenobiotic phase I reactions. Toxicology. 2000;144(1-3):71-81.

13. Penning TM, Drury JE. Human aldo-keto reductases: function, gene regulation, and single nucleotide polymorphisms. Arch Biochem Biophys. 2007;464(2):241-50.

14. Zanger UM, Schwab M. Cytochrome P450 enzymes in drug metabolism: regulation of gene expression, enzyme activities, and impact of genetic variation. Pharmacol Ther. 2013;138(1):103-41.
15. Wirth $\mathrm{H}$, Wermuth B. Immunohistochemical localization of carbonyl reductase in human tissues. $\mathrm{J}$ histochem Cytochem. 1992;40(12):1857-63.

16. Zhu AZ, Zhou Q, Cox LS, Ahluwalia JS, Benowitz NL, Tyndale RF. Gene variants in CYP2C19 are associated with altered in vivo bupropion pharmacokinetics but not bupropionassisted smoking cessation outcomes. Drug Metab Dispos. 2014;42(11):1971-7.

17. Woodcock J, Khan M, Yu LX. Withdrawal of generic budeprion for nonbioequivalence. N Engl J Med. 2012;367(26):2463-5.

18. Benowitz NL, Zhu AZ, Tyndale RF, Dempsey D, Jacob P 3rd. Influence of CYP2B6 genetic variants on plasma and urine concentrations of bupropion and metabolites at steady state. Pharmacogenet Genomics. 2013;23(3):135-41.

19. Connarn JN, Zhang X, Babiskin A, Sun D. Metabolism of bupropion by carbonyl reductases in liver and intestine. Drug Metab Dispos. 2015;43(7):1019-27.

20. Molnari JC, Myers AL. Carbonyl reduction of bupropion in human liver. Xenobiotica. 2012;42(6):550-61.

21. Skarydova L, Tomanova R, Havlikova L, Stambergova H, Solich P, Wsol V. Deeper insight into the reducing biotransformation of bupropion in the human liver. Drug Metab Pharmacokinet. 2014;29(2):177-84.

22. Zhu AZ, Cox LS, Nollen N, Faseru B, Okuyemi KS, Ahluwalia JS, et al. CYP2B6 and bupropion's smoking-cessation pharmacology: the role of hydroxybupropion. Clin Pharmacol Ther. 2012;92(6):771-7.

23. De Morais SM, Wilkinson GR, Blaisdell J, Meyer UA, Nakamura K, Goldstein JA. Identification of a new genetic defect responsible for the polymorphism of (S)-mephenytoin metabolism in Japanese. Mol Pharmacol. 1994;46(4):594-8.

24. Scott SA, Sangkuhl K, Stein CM, Hulot JS, Mega JL, Roden $\mathrm{DM}$, et al. Clinical pharmacogenetics implementation consortium guidelines for CYP2C19 genotype and clopidogrel therapy: 2013 update. Clin Pharmacol Ther. 2013;94(3):317-23.

25. Sim SC, Risinger C, Dahl ML, Aklillu E, Christensen M, Bertilsson L, et al. A common novel CYP2C19 gene variant causes ultrarapid drug metabolism relevant for the drug response to proton pump inhibitors and antidepressants. Clin Pharmacol Ther. 2006;79(1):103-13.

26. Sabatti C, Service SK, Hartikainen AL, Pouta A, Ripatti S, Brodsky J, et al. Genome-wide association analysis of metabolic traits in a birth cohort from a founder population. Nat Genet. 2009;41(1):35-46.

27. Marsh S, King CR, Garsa AA, McLeod HL. Pyrosequencing of clinically relevant polymorphisms. In: Innocenti $\mathrm{F}$, editor. Pharmacogenomics: Methods and protocols. Totowa: Humana Press; 2005. p. 97-114.

28. Damaj MI, Grabus SD, Navarro HA, Vann RE, Warner JA, King LS, et al. Effects of hydroxymetabolites of bupropion on nicotine dependence behavior in mice. J Pharmacol Exp Ther. 2010;334(3):1087-95.

29. Hofmann MH, Blievernicht JK, Klein K, Saussele T, Schaeffeler $\mathrm{E}$, Schwab $\mathrm{M}$, et al. Aberrant splicing caused by single nucleotide polymorphism c.516G $>\mathrm{T}$ [Q172H], a marker of CYP2B6*6, is responsible for decreased expression and activity of CYP2B6 in liver. J Pharmacol Exp Ther. 2008;325(1):284-92.

30. Blume HH, Midha KK. Bio-international 92, conference on bioavailability, bioequivalence, and pharmacokinetic studies. J Pharm Sci. 1993;82(11):1186-9.

31. Jackson AJ, Robbie G, Marroum P. Metabolites and bioequivalence: past and present. Clin Pharmacokinet. 2004;43(10):65572 .

32. Karalis V, Magklara E, Shah VP, Macheras P. From drug delivery systems to drug release, dissolution, IVIVC, BCS, BDDCS, bioequivalence and biowaivers. Pharm Res. 2010;27(9):2018-29.

33. Midha KK, Shah VP, Singh GJ, Patnaik R. Conference report: bio-international 2005. J Pharm Sci. 2007;96(4):747-54.

34. Research FaDACfDEa. Bioequivalence evaluation of innovator and generic bupropion XL products October 12, 2012. Available from: http://www.fda.gov/downloads/drugs/drugsafety/ postmarketdrugsafetyinformationforpatientsandproviders/ ucm323471.pdf. 